\title{
What change in outcomes after cardiac arrest is necessary to change practice? Results of an international survey
}

\section{Nichol, Graham}

2016-10

Nichol , G, Brown , S P , Perkins , G D , Kim , F , Sterz , F, Elrod, J A B , Mentzelopoulos , S , Lyon, R , Arabi , Y, Castren , M , Larsen , P, Valenzuela , T, Graesner , J-T , Youngquist, S , Khunkhlai , N, Wang, H E, Ondrej , F, Fraga Sastrias , J M , Barasa , A \& Sayre, M R 2016, ' What change in outcomes after cardiac arrest is necessary to change practice? Results of an international survey ', Resuscitation , vol. 107 , pp. 115-120 . https://doi.org/10.1016/j.resusc

http://hdl.handle.net/10138/229964

https://doi.org/10.1016/j.resuscitation.2016.08.004

publishedVersion

Downloaded from Helda, University of Helsinki institutional repository.

This is an electronic reprint of the original article.

This reprint may differ from the original in pagination and typographic detail.

Please cite the original version. 


\title{
Clinical paper
}

\section{What change in outcomes after cardiac arrest is necessary to change practice? Results of an international survey ${ }^{\text {is }}$}

\author{
Graham Nichol $^{\mathrm{a}, *}$, Siobhan P. Brown ${ }^{\mathrm{a}}$, Gavin D. Perkins ${ }^{\mathrm{b}, \mathrm{c}}$, Francis Kim ${ }^{\mathrm{a}}$, Fritz Sterz ${ }^{\mathrm{d}}$, \\ Jo Ann Broeckel Elrod ${ }^{a}$, Spyros Mentzelopoulos ${ }^{\mathrm{e}}$, Richard Lyon ${ }^{\mathrm{f}}$, Yaseen Arabi ${ }^{\mathrm{g}}$, \\ Maaret Castren ${ }^{\mathrm{h}}$, Peter Larsen ${ }^{\mathrm{i}}$, Terence Valenzuela ${ }^{\mathrm{j}}$, Jan-Thorsten Graesner $^{\mathrm{k}}$, \\ Scott Youngquist ${ }^{1}$, Nalinas Khunkhlai ${ }^{\mathrm{m}}$, Henry E. Wang ${ }^{\mathrm{n}}$, Franek Ondrej ${ }^{ }$, \\ Juan Manuel Fraga Sastrias ${ }^{\mathrm{p}}$, Anders Barasa ${ }^{\mathrm{q}}$, Michael R. Sayre ${ }^{\mathrm{a}}$ \\ a University of Washington, Seattle, WA, USA \\ ${ }^{\mathrm{b}}$ University of Warwick, Warwick, UK \\ ${ }^{\mathrm{c}}$ Heart of England NHS Foundation Trust, Coventry, UK \\ d Medical University of Vienna, Vienna, Austria \\ e University of Athens Medical School, Athens, Greece \\ ${ }^{\mathrm{f}}$ University of Surrey, Guildford, Surrey, UK \\ ${ }^{g}$ King Saud Bin Abdulaziz University for Health Sciences and King Abdullah International Medical Research Center, Riyadh, Saudi Arabia \\ ${ }^{\mathrm{h}}$ Department of Emergency Medicine and Services, Helsinki University Hospital and Helsinki University, Helsinki, Finland \\ ${ }^{\mathrm{i}}$ University of Otago, Wellington, New Zealand \\ j University of Arizona, Tucson, AZ, USA \\ ${ }^{\mathrm{k}}$ University Hospital Schleswig-Holstein, Germany \\ ${ }^{1}$ University of Utah, Salt Lake City, UT, USA \\ m Department of Emergency Medicine E Narenthorn EMS Center Rajavithi Hospital, Ministry of Public Health, Thailand \\ ${ }^{\mathrm{n}}$ University of Alabama at Birmingham, Birmingham, AL, USA \\ ${ }^{\circ}$ Prague EMS, Prague, Czech Republic \\ p Academia Mexicana de Medicina Prehospitalaria, Mexico \\ ${ }^{q}$ Aga Khan University, Nairobi, Kenya
}

\section{A R T I C L E I N F O}

Article history:

Received 23 December 2015

Received in revised form 1 August 2016

Accepted 4 August 2016

\section{Keywords:}

Cardiac arrest

Survey

Methods

Randomized trails

\begin{abstract}
A B S T R A C T
Background: Efficient trials of interventions for patients with out-of-hospital cardiac arrest (OHCA) should have adequate but not excess power to detect a difference in outcomes. The minimum clinically important difference (MCID) is the threshold value in outcomes observed in a trial at which providers should choose to adopt a treatment. There has been limited assessment of MCID for outcomes after OHCA. Therefore, we conducted an international survey of individuals interested in cardiac resuscitation to define the MCID for a range of outcomes after OHCA.

Methods: A brief survey instrument was developed and modified by consensus. Included were openended responses. The survey included an illustrative example of a hypothetical randomized study with distributions of outcomes based on those in a public use datafile from a previous trial. Elicited information included the minimum significant difference required in an outcome to change clinical practice. The population of interest was emergency physicians or other practitioners of acute cardiovascular research. Results: Usable responses were obtained from 160 respondents (50\% of surveyed) in 46 countries (79\% of surveyed). MCIDs tended to increase as baseline outcomes increased. For a population of patients with $25 \%$ survival to discharge and $20 \%$ favorable neurologic status at discharge, the MCID were median 5 (interquartile range [IQR] 3,10) percent for survival to discharge; median 5 (IQR 2, 10) percent for favorable neurologic status at discharge, median 4 (IQR 2, 9) days of ICU-free survival and median 4 (IQR 2,8 ) days of hospital-free survival.

Conclusion: Reported MCIDs for outcomes after OHCA vary according to the outcome considered as well as the baseline rate of achieving it. MCIDs of ICU-free survival or hospital-free survival may be useful to accelerate the rate of evidence-based change in resuscitation care.
\end{abstract}

(c) 2016 Elsevier Ireland Ltd. All rights reserved.

\footnotetext{
A A Spanish translated version of the abstract of this article appears as Appendix in the final online version at http://dx.doi.org/10.1016/j.resuscitation.2016.08.004.

* Corresponding author.
} 


\section{Introduction}

There is a large variation in the process and outcome of care for patients with out of hospital cardiac arrest (OHCA). ${ }^{1-3}$ Recently, several communities have reported that outcomes after OHCA have improved over time. ${ }^{4-6}$ Now, many patients with cardiac arrest can return to a good quality of life if recognized and treated quickly. This variation in and improvement of outcomes emphasizes the need to conduct efficient randomized trials of interventions to accelerate evidence-based changes in resuscitation practices to improve outcomes for patients with OHCA.

Resources for clinical research are limited. Clinical research related to cardiac arrest is underfunded compared to other common clinical conditions. ${ }^{7}$ There is heterogeneity in outcomes among randomized trials of interventions for patients with cardiac arrest. ${ }^{8}$ The sample size for a trial depends in part on the magnitude of difference in outcomes sought. To optimize use of limited funds, efficient large simple trials of interventions for patients with OHCA should have adequate but not excess power to detect a difference in outcomes. The minimum clinically important difference (MCID) has been defined as the threshold value in outcomes observed in a trial at which patients or providers should choose to adopt a treatment. ${ }^{9}$ If a trial reports a significant difference that is larger than the MCID for an outcome, then providers should likely use that intervention to treat patients. But if a trial reports a difference that is smaller than the MCID for an outcome, then rational providers may not use that intervention because the benefits may not be large enough to be important to patients or providers. To date, there has been limited descriptions of MCID for outcomes after OHCA. ${ }^{10,11}$ Therefore, we conducted an international survey emergency physicians or other practitioners of acute cardiovascular research to define the MCID for a range of outcomes after OHCA, including novel outcomes for trials in patients with cardiac arrest, such as hospital-free survival and intensive care free survival. A secondary object was to estimate sample sizes of trials necessary to detect MCIDs.

\section{Methods}

Survey

A brief survey instrument was developed by several of the authors (GN, GP, FS, FK, MS, SB) and modified by consensus prior to distribution to probe for the minimum clinically important difference for outcomes in trials of interventions in patients with OHCA (see online appendix). Responses were open-ended rather than multiple-choice. The survey was prepared for online completion by using standard electronic data capture software. ${ }^{12}$

Survey questions were preceded by an illustrative example of a hypothetical randomized study to help focus the responses to the questions. MCID were sought for a range of outcomes intended to mimic the distribution of outcomes expected for all patients treated by emergency medical services (EMS) providers; those treated for pulseless electrical activity or asystole; those treated for ventricular fibrillation (VF); and those with VF and spontaneous circulation upon hospital arrival. These outcomes were patterned on those included in the Utstein template for standardized reporting of outcomes after OHCA. ${ }^{13}$

Two additional outcomes were included in the survey. Intensive care morbidity was defined as the number of days alive and permanently out of intensive care (ICU) during the first 30 days post arrest. 'Permanently' was defined as discharged from intensive care without any further readmission. Intensive care includes a ward capable of providing mechanical ventilation but not a ward capable of providing telemetry only. Patients who die before discharge from ICU would be assigned zero days out of intensive care. The day a subject was discharged from the ICU was counted as a full day in the ICU. Similarly, hospital morbidity was defined as the number of days alive and permanently out of hospital up to thirty days post arrest. Again patients who die before discharge will be assigned zero days out of hospital. The distribution of outcomes was estimated from the public use datafile of a previous large randomized trial of interventions in patients with OHCA. ${ }^{14,15}$

Respondents were asked to describe their general characteristics, including age, gender, years since medical school, years in practice and country of residence. No individually identifiable information was collated. The University of Washington Institutional Review Board reviewed this study and determined that it was exempt from human subjects research.

\section{Respondents}

The population of interest was emergency physicians or other practitioners of acute cardiovascular research. Individuals invited to participate had previously published at least one peer-reviewed article related to OHCA. These were supplemented as needed by recommendation of peers to achieve at least two responses from each country. Repeat invitations were sent by electronic mail to non-respondents until at least two responses were obtained from any individual country.

\section{Countries}

We sought participation from individuals in as many countries as possible with the purpose of representing a diversity of medical practices. After we achieved responses from $50 \%$ of individuals, we determined that we had a broad enough set of responses to allow meaningful inferences.

\section{Analysis}

Responses were summarized descriptively ( $\mathrm{R}$ 3.2.1, R Development Core Team available at www.r-project.org; and SAS JMP 11.2.0, SAS Institute, Cary, NC). The median absolute increase in each outcome across the range of baseline rates was used to estimate the number of patients required to detect the MCID in a hypothetical superiority trial. These estimates assumed a single analysis with $90 \%$ power, and two-sided alpha $=0.05$.

\section{Results}

\section{Survey responses}

Participation was sought from 321 individuals in 58 countries. Responses were obtained from 161 (50\% of sample) individuals in 46 countries ( $79 \%$ of sample) that included India, China, Kenya, Nigeria, and South Africa, many of the European Union countries, as well as North and South American countries including Canada, USA, Mexico, and Brazil (Fig. 1). One response was not usable. The total census population represented by respondents was about 4.5 billion people. Responses were reported overall and then by the subgroup of countries in North America ( 3 countries; 36 responses) vs. Europe ( 21 countries; 67 responses) vs. the rest of the world (22 countries; 54 responses).

Table 1 describes the characteristics of the respondents. The majority were male $(n=129,81 \%)$. Most of the respondents were physicians ( $n=131,82 \%$ ). Years in practice were mean $15.9 \pm 12.3$.

Table 2 summarizes the responses to the elicitations of MCID overall and grouped by region. The majority of reported MCIDs were clustered together (i.e. had narrow interquartile range). MCID were not significantly different among North American respondents as compared to those from Europe or the rest of the world. 


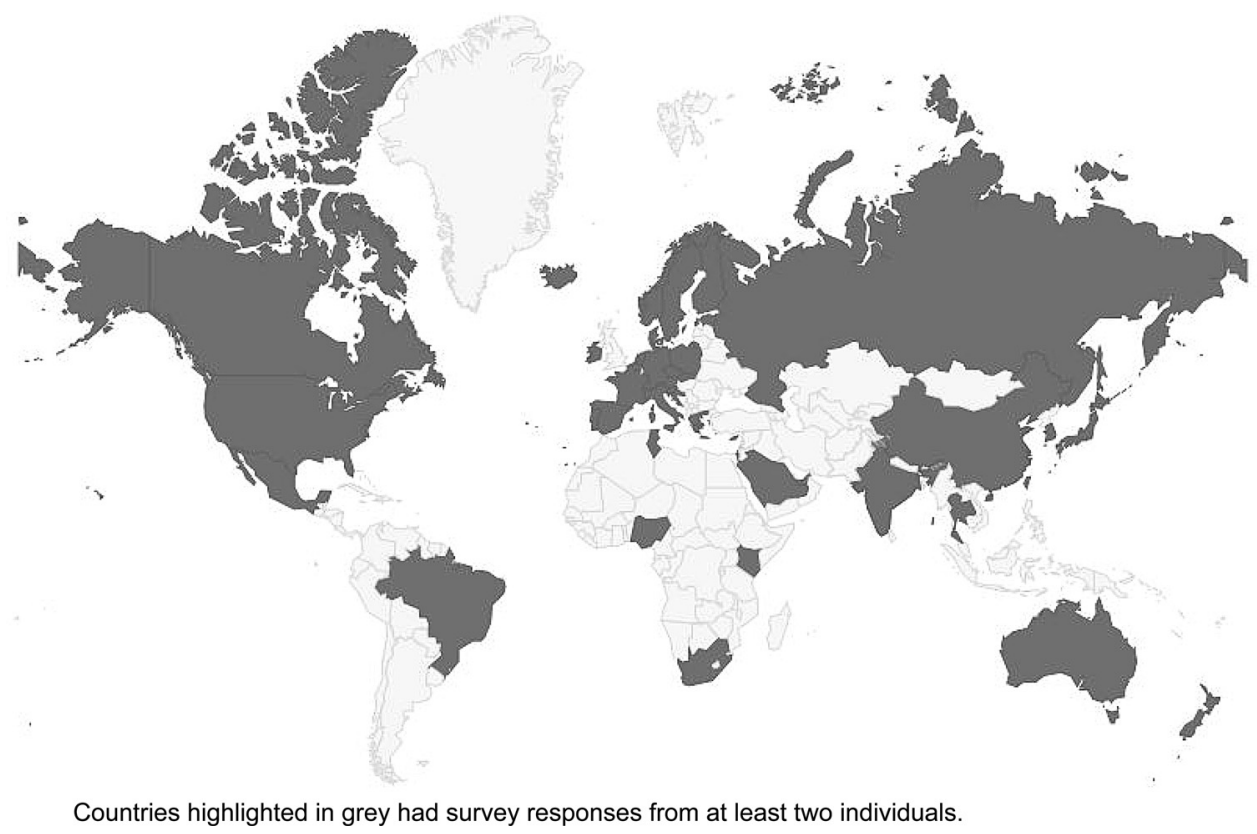

Fig. 1. Participating countries.

Fig. 2 describes the MCID for an absolute increase in favorable neurologic status at discharge as a function of the baseline distribution of favorable neurologic status at discharge. As the baseline outcomes increased, the MCID tended to increase. MCIDs for other outcomes are available (See Supplementary Appendix).

The sample size required to detect an MCID varies according to the population of patients considered (Table 3). Fig. 3 describes the overall number of patients to be enrolled in a trial with $90 \%$ power and two-sided alpha $=0.05$ to detect the MCID for ICU-free days, hospital-free days, survival to discharge and favorable neurologic status at discharge across the baseline distribution of each outcome. Significantly fewer patients were required to detect the MCID for ICU-free days or hospital-free days as compared to survival to discharge or favorable neurologic status at discharge ( $p$ value $<0.001$ ).

In post hoc subgroup analyses of the MCID for survival to discharge in a population with a baseline survival to discharge proportion of $25 \%$, there was no heterogeneity in MCID grouped by male vs. female gender ( $p$ for interaction $=0.14$; mean (SD) MCID of
7.9 (7.9) for males and 5.8 (6.5) for females). However, there was heterogeneity by physician vs. non-physician respondents ( $p$ for interaction $=0.004$; mean (SD) MCID of 8.0 (8.2) for physicians and 4.9 (3.7) for others).

\section{Discussion}

We have defined the MCID by emergency physicians or other practitioners of acute cardiovascular research. These differences vary according to the outcome considered as well as the baseline rate of achieving it.

Future trials can be designed to be large enough to be able to detect the MCID in an outcome. Enrolling too few patients to detect the MCID for an outcome is not sufficient to change clinical practice. Enrolling too many to detect the MCID for an outcome uses resources that can be efficiently reallocated to investigate other interventions. If a significant difference is observed, then the intervention would likely be adopted by rational providers. Conversely,

Table 1

Characteristics of respondents

\begin{tabular}{|c|c|c|c|c|}
\hline & $\begin{array}{l}\text { North America } \\
N=36\end{array}$ & $\begin{array}{l}\text { Europe } \\
N=67\end{array}$ & $\begin{array}{l}\text { Other } \\
N=54\end{array}$ & $\begin{array}{l}\text { Overall } \\
N=160\end{array}$ \\
\hline \multirow[t]{2}{*}{ Age in years, mean $(\mathrm{SD})$, median $(\mathrm{Q} 1, \mathrm{Q} 3)[N=36 ; 67 ; 54 ; 159]$} & $49.0(11.0)$ & $46.9(11.4)$ & $46.3(10.4)$ & $47.0(11.0)$ \\
\hline & $49(39,57)$ & $48(39,55)$ & $45(39,53)$ & $47(39,55)$ \\
\hline Male gender, no. (\%) & $29(81)$ & $50(75)$ & $46(85)$ & $129(81)$ \\
\hline \multicolumn{5}{|l|}{ Primary profession, no. (\%) } \\
\hline MD & $25(69)$ & $59(88)$ & $45(83)$ & $131(82)$ \\
\hline EMS provider & $6(17)$ & $1(1)$ & $2(4)$ & $10(6)$ \\
\hline Nurse & 0 & $(0)$ & $2(4)$ & $2(1)$ \\
\hline Researcher & $4(11)$ & $6(9)$ & $5(7)$ & $14(9)$ \\
\hline Other & $1(3)$ & $1(1)$ & $1(2)$ & $3(2)$ \\
\hline \multicolumn{5}{|l|}{ Clinical experience } \\
\hline Years in practice, mean (SD) & $15.0(13.5)$ & $17.3(11.7)$ & $15.1(12.3)$ & $15.9(12.3)$ \\
\hline $\operatorname{median}(\mathrm{Q} 1, \mathrm{Q} 3)[N=36 ; 65 ; 53 ; 156]$ & $12(1,27)$ & $15(8,25)$ & $14(4,24)$ & $15(6,25)$ \\
\hline Patients with OHCA treated annually, mean $(\mathrm{SD})[N=36 ; 66 ; 52 ; 156]$ & $33.7(53.5)$ & $30.8(44.0)$ & $63.3(155.0)$ & $42.0(97.9)$ \\
\hline Enrolled patients in trial, no. $(\%) 1[N=36 ; 66 ; 54 ; 159]$ & $20(56)$ & $41(61)$ & $22(41)$ & $83(52)$ \\
\hline Led trial, no. (\%) $[N=36 ; 66 ; 54 ; 159]$ & $11(31)$ & $18(27)$ & $14(26)$ & $43(27)$ \\
\hline \multicolumn{5}{|l|}{ Location, no. $(\%)[N=157]$} \\
\hline North America & - & - & - & $37(23)$ \\
\hline Europe & - & - & - & $69(43)$ \\
\hline Other & - & - & - & $54(34)$ \\
\hline
\end{tabular}


Table 2

Reported minimum clinically important differences.

\begin{tabular}{|c|c|c|c|c|c|}
\hline Subgroup & $\begin{array}{l}\text { Outcome } \\
\text { [baseline value] }\end{array}$ & $\begin{array}{l}\text { North America } \\
\text { median (Q1, Q3) }\end{array}$ & $\begin{array}{l}\text { Europe } \\
\text { median (Q1, Q3) }\end{array}$ & $\begin{array}{l}\text { Other } \\
\text { median (Q1, Q3) }\end{array}$ & $\begin{array}{l}\text { Overall } \\
\text { median (Q1, Q3) }\end{array}$ \\
\hline EMS-treated OHCA & $\begin{array}{l}\text { ROSC at ED Arrival [27\%] } \\
\text { Survive } 3 \text { days post-arrest [15\%] } \\
\text { Survive to discharge [9\%] } \\
\text { Good neuro at discharge [6\%] } \\
\text { ICU-free days [1.7 } \pm 6.1] \\
\text { Hospital-free days }[1.2 \pm 4.8]\end{array}$ & $\begin{array}{c}10(5,15) \\
6(3,10) \\
3(2,6) \\
2(1,5) \\
2(1,6) \\
2(1,6)\end{array}$ & $\begin{array}{c}10(5,10) \\
5(3,10) \\
4(2,5) \\
3(2,5) \\
3(1,5) \\
3(1,7)\end{array}$ & $\begin{array}{c}10(5,20) \\
5(5,15) \\
5(2,15) \\
4(2,10) \\
4(1,7) \\
3(1,10)\end{array}$ & $\begin{array}{c}10(5,14) \\
5(3,10) \\
4(2,10) \\
3(2,7) \\
3(1,7) \\
3(1,8)\end{array}$ \\
\hline Non-shockable OHCA & $\begin{array}{l}\text { ROSC at ED arrival [22\%] } \\
\text { Survive } 3 \text { days post-arrest [9\%] } \\
\text { Survive to discharge [3\%] } \\
\text { Good neuro at discharge [2\%] } \\
\text { ICU-free days }[0.7 \pm 4.1] \\
\text { Hospital-free days }[0.5 \pm 3.2]\end{array}$ & $\begin{array}{c}10(5,12) \\
5(3,10) \\
3(1,8) \\
2(1,6) \\
2(1,6) \\
2(1,5)\end{array}$ & $\begin{array}{c}10(5,15) \\
5(3,10) \\
4(2,5) \\
3(1,5) \\
3(1,7) \\
3(1,10)\end{array}$ & $\begin{array}{c}10(5,20) \\
5(3,10) \\
3(2,8) \\
3(2,10) \\
3(1,10) \\
3(1,10)\end{array}$ & $\begin{array}{c}10(5,15) \\
5(3,10) \\
3(2,5) \\
3(1,5) \\
3(1,6) \\
3(1,7)\end{array}$ \\
\hline Shockable OHCA & $\begin{array}{l}\text { ROSC at ED arrival [43\%] } \\
\text { Survive } 3 \text { days post-arrest [36\%] } \\
\text { Survive to discharge [25\%] } \\
\text { Good neuro at discharge [20\%] } \\
\text { ICU-free days [4.9 } \pm 9.3] \\
\text { Hospital-free days }[3.5 \pm 7.4]\end{array}$ & $\begin{array}{c}10(5,15) \\
7(4,13) \\
5(3,6) \\
4(2,6) \\
3(2,5) \\
3(2,5)\end{array}$ & $\begin{array}{c}10(5,13) \\
7(4,10) \\
5(3,7) \\
5(2,10) \\
4(2,6) \\
4(2,8)\end{array}$ & $\begin{array}{r}10(5,19) \\
8(4,15) \\
6(2,13) \\
5(2,11) \\
5(2,10) \\
5(1,10)\end{array}$ & $\begin{array}{c}10(5,15) \\
7(4,12) \\
5(3,10) \\
5(2,10) \\
4(2,9) \\
4(2,8)\end{array}$ \\
\hline OHCA VF, pulse at ED arrival & $\begin{array}{l}\text { Survive } 3 \text { days post-arrest [74\%] } \\
\text { Survive to discharge [53\%] } \\
\text { Good neuro at discharge [ } 43 \%] \\
\text { ICU-free days }[10.5 \pm 11.4] \\
\text { Hospital-free days }[7.5 \pm 9.3]\end{array}$ & $\begin{array}{c}10(4,15) \\
5(3,10) \\
5(3,10) \\
5(2,7) \\
3(2,9)\end{array}$ & $\begin{array}{l}9(5,15) \\
7(5,10) \\
5(4,10) \\
5(2,10) \\
5(2,10)\end{array}$ & $\begin{array}{r}10(5,17) \\
10(4,15) \\
10(3,15) \\
8(2,10) \\
7(2,10)\end{array}$ & $\begin{array}{r}10(5,15) \\
6(4,10) \\
5(3,10) \\
5(2,10) \\
5(2,10)\end{array}$ \\
\hline $\begin{array}{l}\text { OHCA VF, pulse at ED arrival, } \\
\text { survived at least } 4 \mathrm{~h}\end{array}$ & $\begin{array}{l}\text { Survive } 3 \text { days post-arrest [80\%] } \\
\text { Survive to discharge [58\%] } \\
\text { Good neuro at discharge [47\%] } \\
\text { ICU-free days }[11.4 \pm 11.4] \\
\text { Hospital-free days }[8.1 \pm 9.4]\end{array}$ & $\begin{array}{c}10(5,15) \\
5(3,10) \\
5(3,10) \\
4(2,7) \\
3(2,9)\end{array}$ & $\begin{array}{r}10(5,15) \\
6(5,10) \\
5(4,10) \\
5(3,10) \\
5(2,10)\end{array}$ & $\begin{array}{r}10(5,15) \\
10(3,12) \\
7(3,10) \\
6(2,12) \\
7(2,10)\end{array}$ & $\begin{array}{r}10(5,15) \\
6(3,10) \\
5(3,10) \\
5(2,10) \\
5(2,10)\end{array}$ \\
\hline
\end{tabular}

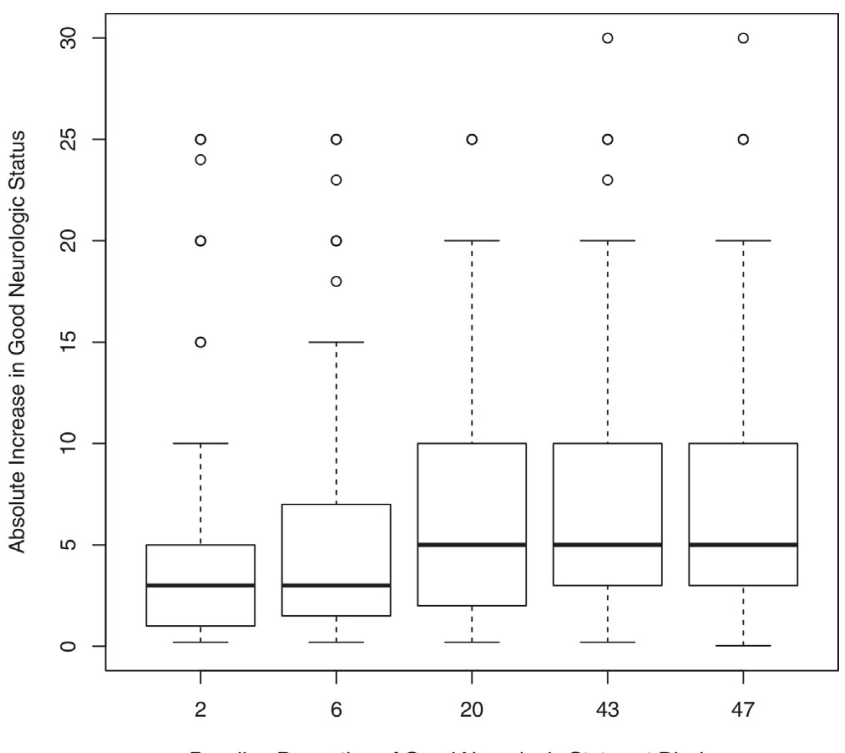

Baseline Proportion of Good Neurologic Status at Discharge

Fig. 2. Minimum clinically important difference for good neurologic status.

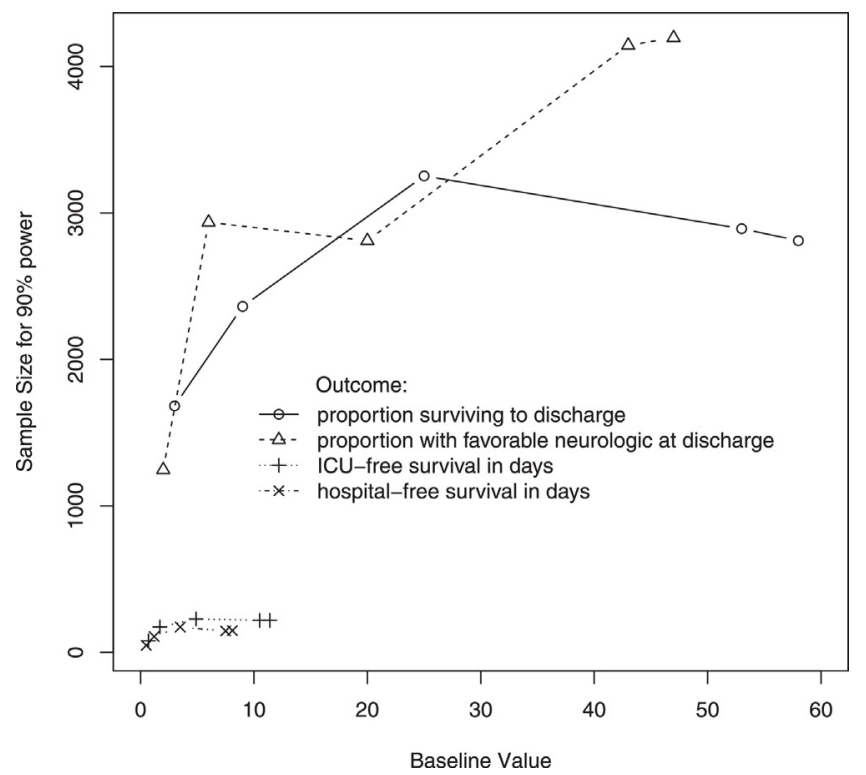

Fig. 3. Sample size required to detect minimum clinically important differences.

Table 3

Sample size for $90 \%$ power to detect median MCID.

\begin{tabular}{|c|c|c|c|c|}
\hline Subgroup & Survival to discharge & Good neuro at discharge & ICU-free days & Hospital-free days \\
\hline EMS-treated OHCA & 1683 & 1247 & 79 & 48 \\
\hline Non-shockable OHCA & 2362 & 2937 & 174 & 108 \\
\hline Shockable OHCA & 3253 & 2811 & 228 & 188 \\
\hline OHCA VF, pulse at ED arrival & 2893 & 4145 & 219 & 146 \\
\hline OHCA VF, pulse at ED arrival, survived at least $4 \mathrm{~h}$ & 2811 & 4196 & 219 & 149 \\
\hline
\end{tabular}

The table shows sample size required to have $90 \%$ power to detect median MCID for baseline values listed in Table 2. 
if a significant difference is not achieved, then limited resources can be reinvested in use of other effective therapies.

The reported MCIDs provide a starting point for reaching consensus on how much of a difference should be demonstrated to warrant a change in clinical practice guidelines or change in clinical practice. Some of the reported MCID are large and have a large variance.

Among hypothetical populations with low (i.e. 5\%) survival to hospital discharge or favorable neurologic status at discharge, reported MCIDs were within $2 \%$ of expected differences in previously completed trials (Table 3). ${ }^{14,15,26}$ For a hypothetical population with ROSC at emergency department arrival of $10 \%$, reported MCIDs were within $5 \%$ of expected differences in survival to hospital admission in previously completed trials. ${ }^{27-29}$ Among hypothetical populations with high (i.e. $40-55 \%$ ) survival to discharge or favorable neurologic status at discharge, reported MCIDs were within $10 \%$ of expected differences in previously completed trials. ${ }^{16,30}$ For traditional outcomes such as admission to hospital, survival to discharge or favorable neurologic status at discharge, consideration of MCIDs may require larger sample sizes than those used in previous trials.

We included two novel outcomes in this survey. ICU-free survival is a composite outcome that captures a treatment effect on both survival and need for intensive care post-resuscitation. Similarly, hospital-free survival is a composite outcome that captures a treatment effect on survival and need for hospital care postresuscitation. A treatment effect in either survival or need for care would justify use of an intervention. Note that other randomized trials that enrolled patients with cardiac arrest have described similar outcomes such as days on a ventilator, in an intensive care unit or in hospital. ${ }^{16-18}$ However the utility of such assessments were limited because they did not account for the differential timing of mortality throughout the hospitalization period. A single trial that enrolled patients with cardiac arrest has reported ICU-free survival during the first month after cardiac arrest. ${ }^{19}$ Importantly, hospital-free survival has been used as an outcome in randomized trials in patients with heart failure, ${ }^{20,21}$ renal failure, ${ }^{22}$ cancer, ${ }^{23}$ or need for intensive care. ${ }^{24}$ As well, hospital-free survival is recommended as an outcome in trials that enroll patients with need for intensive care. ${ }^{25}$ According to the present survey, markedly fewer patients are required to detect the MCID in ICU-free days or hospital-free days. If either of these outcomes is used as the primary outcome in trials of interventions in patients with cardiac arrest, then the pace of evidence-based change in resuscitation care can be accelerated.

ICU days as well as days of ventilation were described in recent trials of interventions in patients with cardiac arrest. ${ }^{16,18}$ Note that such summary measures do not account for the information associated with mortality. Our novel outcomes require a smaller number of subjects required to detect an MCID than traditional outcomes for trials in patients with OHCA (Fig. 3). Thus, ICU-free survival and hospital-free survival offer some potential efficiencies compared to traditional outcomes for trials of interventions in patients with cardiac arrest.

The present study has some limitations. We surveyed a convenience sample of professional individuals interested in cardiac resuscitation without requiring them to have a predetermined level of experience. Surveys of individuals were previously adopted as a method to develop consensus by allowing participants to make considered independent opinions so as to lead to reliable conclusions. ${ }^{31}$ Participants can be selected in multiple ways, including their position in a hierarchy, public acknowledgment or recommendation by other participants. ${ }^{32}$ We did not include patients or caregivers as has sometimes been recommended. ${ }^{33}$ Importantly use of experts versus non-experts is not associated with large difference in survey outcomes. ${ }^{34}$
We did not account for variation in the duration of hospitalization across the health systems or countries of respondents. Nor did we account for variation in the timing of prognosis assessment and withdrawal of life sustaining treatment across the health systems or countries of respondents. Although the Utstein template recommends ${ }^{13}$ and we evaluated survival to discharge, survival to a fixed time point such as one month after cardiac arrest may mitigate some of these variations in practice.

We did not elicit MCID for outcomes assessed after discharge. Patients resuscitated from cardiac arrest may have cognitive impairment at discharge that improves over time. ${ }^{35}$ Some experts have recommended post-discharge assessment of neurologic outcomes among survivors of cardiac arrest as the primary outcome for resuscitation trial. ${ }^{36}$ As well, post-discharge assessment of health-related quality of life facilitates assessment of the costeffectiveness of the intervention. Among patients who consented for follow-up, those who survived to leave hospital achieved good health-related quality of life. ${ }^{37}$ Post-discharge cognition and quality of life were well correlated with neurologic status at discharge. However post discharge assessments are expensive, may be difficult to perform and are susceptible to bias. ${ }^{37}$

In this survey, we sought the MCID for individual outcomes. In practice, clinical trials often evaluate multiple outcomes. Decisions to use or not use a therapy are sometimes based on the totality of the evidence collected in a trial as opposed to whether a significant difference was observed in the primary outcome. If a significant difference in the primary outcome is observed that is smaller than the relevant MCID, it may still be rational to use the intervention if a significant benefit is observed in key subgroups or in secondary outcomes.

The wide range of responses might be interpreted as suggesting that some individuals may have misunderstood the task. We provided the survey only in the English language. We did not restrict responses to those fluent in English, or assess the fluency of the respondents. We can not differentiate whether these extreme values reflect misunderstanding or true belief. The observation that MCID varied by geography suggests that the results may have been influenced by local practice, language fluency, religious beliefs or other factors. Importantly, consensus on science and practice guidelines for treatment of patients with cardiac arrest are developed and disseminated by international collaboration. ${ }^{38,39}$ Since clinicians in multiple countries interpret and apply the results of trials, we sought to elicit responses from a broad range of countries. We sought at least two responses from each country so that we could not identify individual responses. But two responses does not ensure that each country's view was accurately represented.

We explicitly sought MCID for absolute rather than relative percent changes. Alternative presentations of the same risks and risk reductions may impact on the understanding and behavior of care providers, policy makers, and patients. ${ }^{40}$ Relative risk reduction as compared with absolute risk reduction may be perceived to be larger and may be more persuasive. It is unclear whether presenting relative risk reduction is likely to help people make decisions most consistent with their own values or could lead to misinterpretation. MCIDs appear to vary in part based on the method used to elicit them. ${ }^{41,42}$ We did not assess whether alternative presentations would yield results consistent with those observed in the present study.

Some randomized trials include economic evaluations concurrent with the trial by sampling those patients who provide informed consent for an economic sub-study then following them forward over time. ${ }^{6}$ To the best of our knowledge, there is no widely accepted method of calculating the sample size for an economic evaluation. As well, doing so would be limited by variation in the cost-effectiveness threshold (i.e. the incremental 
cost-effectiveness ratio at which an intervention would or would not be considered good value for money) by jurisdiction. Therefore, we explicitly excluded cost from consideration in our survey. ${ }^{7-9}$

Importantly, the source data were from a trial that only enrolled adults. Our results may not apply to children, whom have different etiologies of arrest, therapies, and outcomes compared to adults.

\section{Conclusion}

Reported MCIDs for outcomes in patients with OHCA varies according to the outcome under consideration as well as the baseline rate of achieving it. MCID of ICU-free survival or hospital-free survival may be useful to design and implement efficient trials of interventions in patients with OHCA so as to accelerate the rate of evidence-based change in resuscitation care.

\section{Acknowledgements}

This publication was supported in part by the National Center For Advancing Translational Sciences of the National Institutes of Health under Award Number UL1TR000423 as well as the National Heart Lung Blood Institute under Award Number 5U01 HL077863. The content is solely the responsibility of the authors and does not necessarily represent the official views of these institutions.

\section{Appendix A. Supplementary data}

Supplementary data associated with this article can be found, in the online version, at http://dx.doi.org/10.1016/j.resuscitation. 2016.08.004.

\section{References}

1. Zive D, Koprowicz K, Schmidt T, et al. Variation in out-of-hospital cardiac arrest resuscitation and transport practices in the Resuscitation Outcomes Consortium: ROC Epistry-Cardiac Arrest. Resuscitation 2011;82:277-84

2. Glover BM, Brown SP, Morrison L, et al. Wide variability in drug use in out-ofhospital cardiac arrest: a report from the resuscitation outcomes consortium. Resuscitation 2012;83:1324-30.

3. Nichol G, Thomas E, Callaway CW, et al. Regional variation in out-of-hospital cardiac arrest incidence and outcome. J Am Med Assoc 2008;300:1423-31.

4. Daya MR, Schmicker RH, Zive DM, et al. Out-of-hospital cardiac arrest survival improving over time: Results from the Resuscitation Outcomes Consortium (ROC). Resuscitation 2015;91:108-15

5. Blom MT, Beesems SG, Homma PCM, et al. Improved survival after out-ofhospital cardiac arrest and use of automated external defibrillators. Circulation 2014;130:1868-75.

6. Wissenberg M, Lippert FK, Folke F, et al. Association of national initiatives to improve cardiac arrest management with rates of bystander intervention and patient survival after out-of-hospital cardiac arrest. J Am Med Assoc 2013;310:1377-84

7. Ornato JP, Becker LB, Weisfeldt ML, Wright BA. Cardiac arrest and resuscitation: an opportunity to align research prioritization and public health need. Circulation 2010:122:1876-9.

8. Whitehead L, Perkins GD, Clarey A, Haywood KL. A systematic review of the outcomes reported in cardiac arrest clinical trials: the need for a core outcome set. Resuscitation 2015:88:150-7.

9. Jaeschke R, Singer J, Guyatt GH. Measurement of health status. Ascertaining the minimal clinically important difference. Control Clin Trials 1989;10:407-15.

10. Stiell IG, Hebert PC, Wells GA, et al.Vasopressin versus epinephrine for inhospital cardiac arrest: a randomised controlled trial. Lancet 2001;358:105-9.

11. Stiell IG, Wells GA, Field B, et al. Advanced cardiac life support in out-of-hospital cardiac arrest. New Engl J Med 2004;351:647-56

12. Harris PA, Taylor R, Thielke R, Payne J, Gonzalez N, Conde JG. Research electronic data capture (REDCap) - a metadata-driven methodology and workflow process for providing translational research informatics support. J Biomed Inform 2009;42:377-81.

13. Perkins GD, Jacobs IG, Nadkarni VM, et al. Cardiac Arrest and Cardiopulmonary Resuscitation Outcome Reports: Update of the Utstein Resuscitation Registry Templates for Out-of-Hospital Cardiac Arrest: A Statement for Healthcare Professionals From a Task Force of the International Liaison Committee on Resuscitation (American Heart Association, European Resuscitation Council, Australian and New Zealand Council on Resuscitation, Heart and Stroke Foundation of Canada, InterAmerican Heart Foundation, Resuscitation Council of Southern Africa, Resuscitation Council of Asia); and the American Heart
Association Emergency Cardiovascular Care Committee and the Council on Cardiopulmonary, Critical Care, Perioperative and Resuscitation. Circulation 2015;132:1286-300.

14. Aufderheide TP, Nichol G, Rea TD, et al. A trial of an impedance threshold device in out-of-hospital cardiac arrest. New Engl J Med 2011;365:798-806.

15. Stiell IG, Nichol G, Leroux BG, et al. Early versus later rhythm analysis in patients with out-of-hospital cardiac arrest. New Engl J Med 2011;365:787-97.

16. Nielsen N, Wetterslev J, Cronberg T, et al. Targeted temperature management at 33 degrees $C$ versus 36 degrees C after cardiac arrest. New Engl J Med 2013;369:2197-206.

17. Mentzelopoulos SD, Zakynthinos SG, Tzoufi M, et al. Vasopressin, epinephrine and corticosteroids for in-hospital cardiac arrest. Arch Int Med 2009;169:15-24.

18. Mentzelopoulos SD, Malachias S, Chamos C, et al. Vasopressin, steroids, and epinephrine and neurologically favorable survival after in-hospital cardiac arrest: a randomized clinical trial. J Am Med Assoc 2013;310:270-9.

19. Deye N, Cariou A, Girardie P, et al. Endovascular versus external targeted temperature management for patients with out-of-hospital cardiac arrest: a randomized controlled study. Circulation 2015;132:182-93.

20. Sanders-van Wijk S, Maeder MT, Nietlispach F, et al. Long-term results of intensified, N-terminal-pro-B-type natriuretic peptide-guided versus symptomguided treatment in elderly patients with heart failure: five-year follow-up from TIME-CHF. Circulation Heart Fail 2014;7:131-9.

21. Smith RF, Germanson T, Judd D, et al. Plasma norepinephrine and atrial natriuretic peptide in heart failure: influence of felodipine in the third Vasodilator Heart Failure Trial. V-HeFT III investigators. J Card Fail 2000;6:97-107.

22. Wang AY, Bellomo R, Ninomiya T, et al. Angiotensin-converting enzyme inhibitor usage and acute kidney injury: a secondary analysis of RENAL study outcomes. Nephrology (Carlton) 2014;19:617-22.

23. Kondo K, Sakamoto J, Nakazato $\mathrm{H}$, et al. A phase III randomized study comparing doxifluridine and 5-fluorouracil as supportive chemotherapy in advanced and recurrent gastric cancer. Oncol Rep 2000;7:485-90.

24. Pontes-Arruda A, Martins LF, de Lima SM, et al. Enteral nutrition with eicosapentaenoic acid, gamma-linolenic acid and antioxidants in the early treatment of sepsis: results from a multicenter, prospective, randomized, double-blinded controlled study: the INTERSEPT study. Crit Care 2011;15:R144.

25. Young P, Hodgson C, Dulhunty J, et al. End points for phase II trials in intensive care: recommendations from the Australian and New Zealand Clinical Trials Group consensus panel meeting. Crit Care Resuscit 2012;14:211-5.

26. Jacobs IG, Finn JC, Jelinek GA, Oxer HF, Thompson PL. Effect of adrenaline on survival in out-of-hospital cardiac arrest: a randomised double-blind placebocontrolled trial. Resuscitation 2011;82:1138-43.

27. Gueugniaud PY, David JS, Chanzy E, et al. Vasopressin and epinephrine vs. epinephrine alone in cardiopulmonary resuscitation. New Engl J Med 2008;359:21-30.

28. Dorian P, Cass D, Schwartz B, Cooper R, Gelaznikas R, Barr A. Amiodarone as compared with lidocaine for shock-resistant ventricular fibrillation. New Engl J Med 2002;346:884-90.

29. Kudenchuk PJ, Cobb LA, Copass MK, et al. Amiodarone for resuscitation after out-of-hospital cardiac arrest due to ventricular fibrillation. New Engl J Med 1999;341:871-8.

30. Kim F, Nichol G, Maynard C, et al. Effect of prehospital induction of mild hypothermia on survival and neurological status among adults with cardiac arrest: a randomized clinical trial. J Am Med Assoc 2014;311:45-52.

31. Dalkey N, Helmer D. An experimental application of the Delphi method to the use of experts. Manage Sci 1963;9:458-67.

32. Mead D, Moseley L. The use of Delphi as a research approach. Nurse Res 2001:8:4-23.

33. Sumsion T. The Delphi technique: an adaptive research tool. Br J Occup Ther 1998;61:153-6.

34. Sackman H. Delphi critique: expert opinion, forecasting and group process. Lexington, MA: Lexington Books; 1975.

35. Roine RO, Kajaste S, Kaste M. Neuropsychological sequelae of cardiac arrest. Am Med Assoc 1993;269:237-42.

36. Becker LB, Aufderheide TP, Geocadin RG, et al. Primary outcomes for resuscitation science studies: a consensus statement from the American Heart Association. Circulation 2011;124:2158-77.

37. Nichol G, Guffey D, Stiell IG, et al. Post-discharge outcomes after resuscitation from out-of-hospital cardiac arrest: a ROC PRIMED substudy. Resuscitation 2015;93:74-81.

38. Nolan JP, Hazinski MF, Billi JE, et al. Part 1: executive summary: 2010 International Consensus on Cardiopulmonary Resuscitation and Emergency Cardiovascular Care Science With Treatment Recommendations. Resuscitation 2010;81(Suppl. 1):e1-25.

39. Field JM, Hazinski MF, Sayre MR, et al. Part 1: executive summary: 2010 American Heart Association Guidelines for Cardiopulmonary Resuscitation and Emergency Cardiovascular Care. Circulation 2010;122(18 Suppl. 3):S640-56.

40. Akl EA, Oxman AD, Herrin J, et al. Using alternative statistical formats for presenting risks and risk reductions. Cochrane Database Syst Rev 2011;3:CD006776.

41. van Walraven C, Mahon JL, Moher D, Bohm C, Laupacis A. Surveying physicians to determine the minimal important difference: implications for sample-size calculation. J Clin Epidemiol 1999;52:717-23.

42. Copay AG, Subach BR, Glassman SD, Polly Jr DW, Schuler TC. Understanding the minimum clinically important difference: a review of concepts and methods. Spine J 2007;7:541-6. 